\title{
Corneal collagen cross-linking procedures
}

\author{
Cristina Nicula*, Nicula Dorin, Pop Radu Nicolae and Rosca Cosmin \\ OCULENS Ophthalmology Private Clinic - No. 7, Cluj-Napoca, Romania
}

\begin{abstract}
Objective: to present corneal collagen corsslinking techniques. Corneal collagen cross-linking (CXL) is a procedure used to slow down or arrest the progression of keratoconus in order to avoid or, at least delay the necessity of keratoplasty. CXL means photopolimerisation of the stromal fibrillar tissue, in order to increase their stiffness and resistance to the corneal ectasia. CXL is a process mediated by photo oxidation between an ultraviolet A light and riboflavin.

Evidence reviewed: In the 1970s, Siegel et al. presented that crosslinking reactions where lysyl oxidase catalyzed the formation of crosslinking aldehydes in collagen and elastin. The procedure was later developed in 1990 by Theo Seiler who used a UVA light and a photo sensitizer (typically riboflavin) to strengthen bonds in the cornea.

Findings: Instruments used in cross-linking: Initial, Wollensak et al., in 2003, used a 370-nm UV light diodes with a potentiometer regulating the voltage, in the present being available: the XLink TM; the CBM Vega XLink Crosslinking System; the LightLink CXL TM; the UV-X TM 2000 Crosslinking System; the KXL TM System. The procedures used today are: Epi-Off Cross-linking technique (standard procedure); CXL with hypo-osmolar riboflavin solution; Epithelium-on CXL technique; Accelerated cross-linking; Iontophoresis Cross-Linking; Contact Lens-Assisted Cross-Linking; LASIK-Xtra; Topography-guided PRK and CXL; Intrastromal Corneal Ring Segments and CXL; Epithelial Island Cross-Linking; Orthokeratology and CXL.

The clinical applications of CXL are: corneal ectasia; corneal infections; chemical burns; bullous keratopathy and other causes of corneal edema; LASIK and CXL; PRK and CXL; intra-corneal stromal rings and CXL; scleral CXL (experimental study).

Conclusions and relevance: There are no known side effects for the corneal endothelium, lens and retina. Cross-linking treatment does not exclude the possibility of keratoplasty. Cross-linking is a safe and efficient method of treatment in corneal ectasia in order to stop or arrest the progression of conus
\end{abstract}

\section{Introduction}

Corneal collagen cross-linking (CXL) means photopolimerisation of the stromal fibrillar tissue, in order to increase their stiffness and resistance to the corneal ectasia, through the combined action of the photosensitizing substance (riboflavin - B2) with the irradiation of the UV light performed with an illuminator in a solid state of UVA kind.

\section{History of corneal cross-linking}

In 1970s, Siegel et al. presented that crosslinking reactions where lysyl oxidase catalyzed the formation of crosslinking aldehydes in collagen and elastin $[1,2]$.

In 1990, Theo Seiler used a UV light and a photo sensitizer (typically riboflavin, Vitamin B2) to strengthen bonds in the cornea [3].

In 1997, Spoerl et al. used a similar principle to attempt an induction of corneal crosslinking (CXL), aiming to increase corneal stiffness [4].

Wollensak et al. [5] demonstrated that following central removal of the epithelium, photosensitizing riboflavin drops were applied and the eyes exposed to UVA light $\left(370 \mathrm{~nm}, 3 \mathrm{~mW} / \mathrm{cm}^{2}\right)$ at a $1 \mathrm{~cm}$ distance for 30 minutes. Clinical follow-up showed that keratoconus stopped progressing in all eyes, and in $70 \%$ of the eyes a regression of keratometric and refractive values had been observed.

\section{Mechanism of action for cross-linking}

CXL is a process mediated by photo oxidation between UVA light $(370 \mathrm{~nm})$ and riboflavin (B2 vitamin). UVA light activates riboflavin into triplet, which in turn produces reactive oxygen species (ROS) including singlet oxygen. ROS reacts with collagen fibril molecules in corneal stroma and enhances the mechanical strength of cornea by forming new chemical bonds between aminoacids and groups of collagen fibril molecules [6]. Riboflavin also plays as a filter to reduce UVA penetrate cornea (Figure 1).

\section{Goal of cross-linking}

The goal of CXL is to slow down or arrest the progression of keratoconus avoiding, or at least delaying the necessity of keratoplasty. The rationale of the procedure is supported by the fact that very few young diabetic patients are affected by keratoconus. In the rarest of occasions, pre-existing development of keratoconus before the onset of diabetes does not show any progression due to the natural crosslinking effect of glucose (chemical cross-linking).

\section{Principle of cross-linking}

Photopolymerization using the UV-light was found to be the most promising technique to achieve cross-links in connective tissue.

Correspondence to: Dr. Cristina Nicula, MD; PhD, Associate Professor, ClujNapoca University Ophthalmology Clinic, Cluj County Hospital - No. 3-5, Clinicilor Street, 400006, Cluj-Napoca, Romania, Tel: +40 722849 575; E-mail: niculacristina65@yahoo.com

Key words: collagen, corneal ectasia, keratoconus, cross-linking, corneal infections Received: October 06, 2016; Accepted: October 25, 2016; Published: October 28,2016 


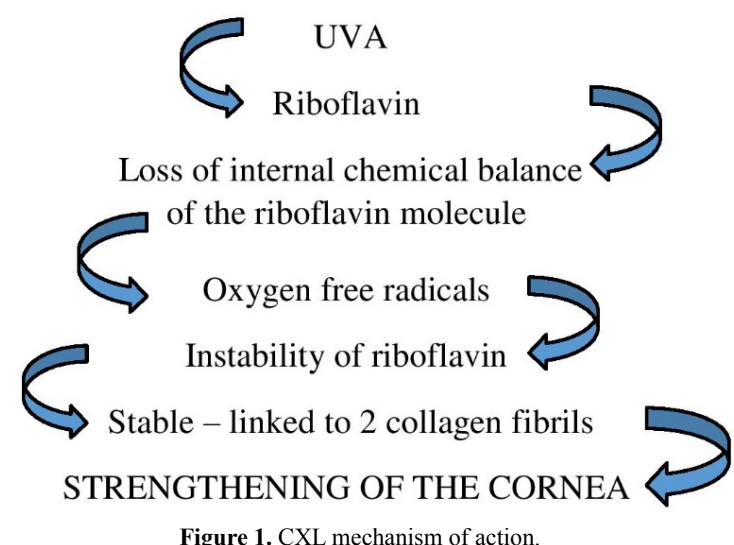

Photopolymerization is activated by means of a non-toxic and soluble photomediator and a wavelenght which is absorbed strongly enough to protect deeper layers of the eye (riboflavin).

\section{Biomechanical changes in the cornea after CXL}

Andreasson et al. showed that the biomechanical strenght of the cornea is abnormally low in keratoconus [7]. Elsheikh, Hadley, Krueger and Seiler demonstrated that keratoconus rarely occurs in instances where corneal stiffening is increased by enhanced collagen CXL (elderly, diabetes) [8-11].

The basis of enhanced biomechanical strength in cornea after CXL is represented by the formation of covalent crosslinks after the action of riboflavin on the de-epithelized surface of the cornea with the exposure of UVA light. Beyond the forming of crosslinks, the free radicals interact with amino-acids in the vicinity of collagen molecules resulting the formation of strong chemical bounds [12].

\section{Are cross-links confined to collagen? Do they occur nonspecifically in tissue?}

It was not yet demonstrated. In theory collagen fiber's surfaces are too widely separated to allow direct interfibrillar linkages. Corneal collagen associates with other bridging collagens and proteoglycan molecules that causes indirect interfibrillar cross-linking via these molecules.

Müller et al. [13] showed that cross-linked corneas swell less than normal. In their study they showed that riboflavin - dextran reduces the corneal thickness of sheep, up to $17 \%$ in 35 minutes of exposure. The question was the resistance to stromal swelling in CXL-treated corneas. The resistance to stromal swelling in CXL - treated corneas is due to presence of dextran indirect interfibrillar CXL. Wollensak et al. [5] showed in their studies that CXL stops the progression of keratoconus or induces slight regression.

Braun et al. [14] presented the corneal rigidity after CXL and showed a decrease in corneal elasticity after riboflavin /UVA CXL (measured with contact ultrasonic device) [14].

Luce et al. [15] presented that corneal hysteresis is an indicator of corneal viscoelasticity evaluated with the Ocular Response Analyzer. Albe [16] and Zadok [12] evaluated the corneal hysteresis after CXL. They presented a study that showed an increased corneal hysteresis after CXL in ovine corneas. They showed that biomechanical measurements may be influenced by changes in parameters during CXL (thickness and hydration).

Spoerl et al. [4] measured the biomechanical stress - strain from cross-linked corneas. The results showed stiffening after treatment and the increase of the corneal rigidity, at humans, with $320 \%$ [4]. A long term follow-up showed that the stiffening effect is maintained over 8 months [17]. In time, long term durability of the strengthening effect is present.

\section{Does CXL promote artificial aging?}

CXL increases corneal stiffness and resistance to enzymatic digestion [18] and also alters the cornea's behavior under thermal, hydrostatic plus electrophoretic stress [19]. This means that the exact magnitude of its clinical effects cannot be quantified.

Marshall et al. [20], in a study, used corneas that underwent epithelial debridement alone, corneas with epithelial debridement with CXL and epithelial debridement with CXL with glutaraldehide $10 \%$.

The results showed an increase in corneal stiffness linear with age and Young's corneal modulus increased 4,3 times. This means that CXL ages the cornea 600 years in approximately 600 seconds [20].

\section{Cross-linking instruments}

Initial, Wollensak et al. [5], in 2003, used a 370-nm UV light diodes (Roithner Lasertechnik, Vienna, Austria) with a potentiometer regulating the voltage [5].

In the present are available:

- The XLink TM (Optos, Dunfermline, UK) has an intensity range of $0.5-5 \mathrm{mw} / \mathrm{cm}^{2}$ and is used in standard 30-min CXL procedures.

- The CBM Vega XLink Crosslinking System (Carleton Optical, Chesham, UK), designed for standard 30-min CXL, was used effectively in several clinical studies [21,22].

- The LightLink CXL TM (LightMed, San Clemente, Calif., USA) has a wide range of irradiance between 0.5 and $30 \mathrm{mw} / \mathrm{cm}^{2}$, allowing a choice of various treatment protocols from 3 to 30 minutes.

- The UV-X TM 2000 Crosslinking System (IROC Innocross, Zurich, Switzerland) has a maximal intensity of $12 \mathrm{mw} / \mathrm{cm}^{2}$ and can be used for a 10-min accelerated CXL procedure.

- The KXL TM System (Avedro, Waltham, Mass., USA) is able to produce a light intensity of $30 \mathrm{~mW} / \mathrm{cm}^{2}$, enabling ultrafast accelerated CXL with less than 3 minutes of UVA exposure.

\section{Types of cross-linking techniques}

There are several CXL techniques: Epi-Off Cross-linking (CXL) technique (Standard procedure), CXL with hypo-osmolar Riboflavin solution, Epi-On CXL technique, Accelerated CXL, Iontophoresis CXL, Contact Lens-Assisted Cross-Linking, LASIK-Xtra, Topographyguided PRK and CXL, Intrastromal Corneal Ring Segments and CXL, Epithelial Island Cross-Linking, Orthokeratology and CXL

\section{Ocular examination before cross-linking}

Discussion with the patient about the CXL procedure (Preoperative Counselling) is very important. It has to be told to the patient that the goal of CXL is not a refractive endpoint, it is a procedure that stops the ectasia, does not give back sight. It has to be explained the technique and its effects - limits further progression of the corneal ectasia. We 
have to present the fact that spectacles or contact lenses will still be required after the procedure, but the patient will be able to continue his lifestyle and job.

Present the postoperative course - haze, pain, delay in reepithelisation, infection prevention, sterile infiltrates, tear dysfunction. The rigid gas permeable contact lens (RGP) must be removed 2 weeks before CXL. Vitamin C (antioxidant) will be applied discontinued 1 week before CXL in patients with atopic eye disorders or poor tear function.

The effect of CXL may take 3 to 6 months. We have to explain that after CXL the patient will note a slightly loss of visual acuity.

Ocular examination:

- Uncorrected (UC VA) and best corrected (BC VA) visual acuity

- Ocular refraction

- Keratometry (must be less than 60D)

- Corneal topography (Pentacam)

- Pachymetry (at least $400 \mu$ )

- Endothelial cells count

\section{Cross-linking procedures}

Epi-Off Cross-linking (CXL) technique (Standard procedure)

- The standard protocol consists in:

a. Sterile opening, in the surgery room, of the ophthalmic solution of riboflavin $0,1 \%$ - dextran $20 \%$

b. Verification of the power of the illuminator UVA array in a solid state CBMX linker with a UVA power meter

c. Topical anesthesia - 3-4 drops, 15-20 minutes before CXL

d. Removal of the corneal epithelium on a $9 \mathrm{~mm}$ diameter

e. Instillation of a drop of alcaine

f. Instillation of riboflavin $0,1 \%$ every $3 \mathrm{~min}$ for 30 minutes before the irradiation

g. Corneal irradiation of central $9 \mathrm{~mm}$ through the CMBX linker plus instillation of riboflavin $0,1 \%$ every 3 minutes for 30 minutes;

h. Instillation of antibiotics and steroids;

i. Therapeutic contact lens for 3-4 days

- Postoperative management:

a. A therapeutic contact lens is applied for 4-5 days

b. Use of antibiotics plus steroids and lubricants for 4 to 6 weeks

c. Postoperative check-up at 28,48 hours and at day $4-5$ to remove the contact lens

d. The follow up is at 6 weeks and 3, 6, 9, 12 months after CXL

- Complications may appear, such as:

Ocular pain, haze, aseptic corneal infiltrates, delayed corneal healing

- The role of Riboflavin is:

1. absorption and concentration of the UV radiation
2. is a photosensibilizing agent for the production of a kind of reactive oxygen (singlet oxygen

3. for endothelial protection

- The role of Dextran T 500 is:

Riboflavin 0,1\% solution contains Dextran T 500 20\%

1. Maintains the osmolarity

- Corneal stroma osmolarity is $380-420 \mathrm{mosmol} / \mathrm{l}$

- Riboflavin 0,1\% - Dextran 20\% osmolarity is 400 mosmol/1

2. Avoids corneal soaking and swelling during the treatment

\section{CXL with hypo-osmolar riboflavin solution}

The modified protocol is applied in thin corneas (advanced progressive keratectasia). It uses the hypo-osmolar riboflavin solution $0,1 \%$, that does not contain dextran. It starts with the removal of the epithelium. The next step is instillation of iso-osmolar riboflavin solution for 30 minutes.

After, the corneal stromal thickness is measured by ultra sound pachimetry. If the cornea is under 400 microns, hypo-osmolar riboflavin is applied every 20 seconds for 5 minutes. The corneal thickness is checked again. If the is still under 400 microns, hypoosmolar riboflavin is still applied.

\section{Epithelium-on CXL technique - trans-epithelial tensioactive mediated CXL}

Is the protocol of Roberto Pinelli and Elschawaf [24]. Uses riboflavin that contains benzalkonium chloride (BAK) and Gentamicin which is applied directly onto the intact epithelium. The mechanism of action is that the BAK changes the surface tension and allows riboflavin to penetrate the cornea.

There are some advantages:

It is less invasive, with fewer complications and it increases the patient's comfort. [24]

\section{- Results:}

There was visual improvement and no progression after treatment, but the effect of CXL was lower. However, the effect of "epithelium-on" CXL varies from "less effective than standard CXL" [25] to "moderately effective" [26] to "appearing to stop keratoconus progression, with a statistically significant improvement in visual and topographic parameters" [27]. Is a useful technique, in special cases, when epithelial debridement should be avoided, such as in patients with dry eyes, uncooperative patients, patients with very thin corneas and pediatric patients.

\section{Accelerated cross-linking}

Accelerated cross-linking, in which the UV light is delivered at a higher intensity over shorter periods of time, is growing in popularity. Initial published reports indicate that this is a safe and effective alternative to the traditional Dresden protocol, but larger studies are needed to understand the optimal parameters. Combining accelerated treatments with pulsing of light and supplemental oxygen may be even more effective. Three multicenter studies in the United States are looking at the efficacy of accelerated cross-linking. Ultraviolet power is increased typically from 3 to 30 milliwatts, and early results are encouraging. 


\section{Iontophoresis cross-linking}

It is a noninvasive technique in which a weak electric current is used to enhance the penetration of electrically charged molecules into tissue. It's safety and efficacy of delivering drugs through cornea and into other ocular tissues had been proven $[28,29]$. Riboflavin is suitable for the technique of iontophoresis, due to small molecular weight, high solubility in water and being negatively charged at physiological $\mathrm{pH}$.

Arboleda et al. [30] showed that iontophoresis was a good candidate for riboflavin delivery into corneal stroma, but the formulation should be in a saline buffer instead of hyperosmotic dextran. Mencucci et al. demonstrated that morphological and biomolecular changes of corneas treated with ionto-CXL at $10 \mathrm{~mW} / \mathrm{cm}^{2}$ for 9 minutes were similar to corneas treated with standard CXL at $3 \mathrm{~mW} / \mathrm{cm}^{2}$ for 30 minutes.

\section{Contact lens-assisted cross-linking}

Jacob et al. presented the procedure for thin corneas (corneal thickness less than $400 \mu \mathrm{m}$ after epithelial removal). The procedure starts with epithelial abrasion, then the isoosmolar riboflavin $0.1 \%$ with dextran is applied every 3 minutes for 30 minutes. An ultraviolet barrier-free soft contact lens $(0.09 \mathrm{~mm}$ thickness, $14 \mathrm{~mm}$ diameter) soaked in isoosmolar riboflavin $0.1 \%$ for 30 minutes is placed on the cornea.

Intraoperative minimum corneal thickness changes were recorded with ultrasound pachymetry and optical coherence tomography. After illumination, the riboflavin-soaked contact lens is removed. Silicon hydrogel bandage contact lens was applied on the cornea until reepithelialization.

\section{LASIK - Xtra}

Procedure: Recognizing the enormous potential safety benefit in restoring the strength of corneas weakened by Lasik, Avedro's team began to investigate the limitations associated with standard crosslinking. The Avedro team made a breakthrough discovery that reduces cross-linking time from one-hour to a few minutes and led to the development of Avedro's "CXL System" for accelerated cross-linking and the "Lasik-Xtra procedure" for prophylactically cross-linking during Lasik surgery.

Lasik-Xtra has the added advantage of being able to apply the riboflavin directly into the Lasik flap interface, eliminating the need to remove the epithelium and to prophylactically cross-link in five minutes during a Lasik procedure. This procedure has an increased flap adhesion.

Mi et al. [33] showed that the flap adhesion has an increased strength to the stromal bed. Todani et al. [34] presented that epithelial cells have a tendency to show in-growth, but the adherence of the flap could reduce or eliminate epithelial cell in-growth under the flap.

Averdo has performed similar experiments using a load cell for small force measurements which showed similar results of increased flap adhesion following cross-linking. This effect could result in a quicker stabilization of the flap-bed interface and reduce the incidence of epithelial in-growth.

Results: According to John Kanellopoulos [35] , prophylactic cross-linking during Lasik results in no refractive effect from crosslinking and "appears to be a safe and effective adjunct treatment against potential ectasia”.

\section{Topography-guided PRK and CXL (Athens protocol)}

Procedure: In 2011, Kanellopoulos and Binder presented a combination treatment using simultaneous CXL and PRK in patients with post laser ectasia [36]. The goal was to use Photorefractive Keratectomy (PRK) to improve visual outcomes by normalizing the corneal surface, reducing irregular astigmatism and potentially reducing the refractive error, in addition to the corneal stabilization effect of corneal CXL.

Results: The results showed improvement at the end of followup in uncorrected distance visual acuity (UC VA) and corrected distance visual acuity (CD VA) to $20 / 45$ or better and topographic improvement. This treatment protocol is commonly referred to as the "Athens protocol"

\section{Intrastromal corneal ring segments and CXL}

As a vision-correcting method, intrastromal corneal ring segments (ICRS) which were designed originally for the correction of mild to moderate myopia, are now being investigated to correct keratoconus without central corneal scarring [37]. CXL strengthens the biomechanical properties of cornea without significantly changing its shape. Combining two methods would be a logical solution to gain the benefits of both. To achieve better effect, ICRS implantation should be performed first so the segments can reshape the cornea without restriction. The optimum interval between ICRS and CXL in combined treatment is uncertain, and ophthalmologists had different interval time [38-40].

Further studies can be planned to compare the effectiveness of different combinations.

\section{Epithelial island cross-linking}

The procedure is "epithelial island cross-linking (EI-CXL) with customized pachymetry-guided epithelial” [41]. The epithelial island protects the thin apical cornea from the UV radiation and its borders and provides a refraction of UVA rays deviating their impact in an intermediate stromal level. The Mazzotta Cosimo and Ramovecchi study showed the EI-CXL technique is safe, efective and reduces the patient's discomfort. One month after EI-CXL, in vivo laser scanning confocal microscopy (IVCM) demonstrated keratocyte's apoptosis under the epithelial island at $150 \mu \mathrm{m}$ of depth on average range of 130 $-170 \mu \mathrm{m}$ and in the paracentral and de-epithelialized ring at $250 \mu \mathrm{m}$ depth on average of $230-270 \mu \mathrm{m}$, suggesting that the effect of crosslinking under epithelial island may be weaker [41].

\section{Orthokeratology and CXL}

CXL stabilizes the outcome of corneal reshaping and shows improvement of visual acuity in patients with keratoconus after orthokeratology treatment. Siena group protocol shows that it is not able to stabilize the orthokeratology molding effect [42].

\section{Clinical applications of cross-linking}

The clinical applications of cross-linking are:

a. Corneal ectasia - keratoconus - different stages - pellucid marginal degeneration

- iatrogenic: after LASIK

b. Corneal infections 

c. Chemical burns
d. Bullous keratopathy and other causes of corneal edema
e. LASIK and CXL
f. PRK and CXL
g. Intra-corneal stromal rings and CXL
g. Scleral CXL (experimental study)

\section{CXL in Keratoconus}

- Topography: The frontal apical elevation showed a significant reduction, starting from the $2^{\text {nd }}$ month after surgery. The spheric aberration and high orders does not show statistically significant variations. The coma aberration is highly reduced from the first month after CXL [44].

- Keratometric values: Showed a regression of aproximatevly 2D in 70\% of patients, after 3-6 months from CXL. [43]. Caporosi et al. [44] Showed a mean K reduction of 2.1D.

- $\quad$ Refractive errors: Were reduced with 1,14D [19]. Dresda's study showed a reduction of spherical equivalent of 2,5D.

- Pachymetry (ultrasonic): Showed a little increase of the corneal thickness in the first month. After 3 months no significant changes observed.

- UCVA and BCVA: Was improved in $68 \%$ of cases [43]. At 1 month 3 Snellen lines increase at the UCVA and 1,2 Snellen lines at BCVA. At 3 months 3,6 Snellen lines increase at the UCVA and 1,6 Snellen lines at BCVA.

- Endothelial cell count: Presented no significant changes.

\section{CXL in pellucid marginal degeneration}

In pellucid marginal degeneration (PLE), corneal thinning is more peripheral than in keratoconus (KCN) [45]. Koller showed that the depth of the CXL effect $3 \mathrm{~mm}$ away from the center of the cornea decreases to $65 \%$ of the central depth. In conclusion, the intended depth of CXL using current light sources is achieved only within the central area of the cornea, and in order to provide CXL to the peripheral cornea, the ultraviolet beam either should have an improved intensity profile or may have to be decentered [46].

Greenstein presented clinical trial, examining the 1-year effect of CXL in 99 eyes with KCN and PLE. This trial showed a decreased flattening effect following CXL in peripheral cones when compared with flattening results for central cones [47].

Lamy presented a 2-year series evaluating $68 \mathrm{KCN}$ eyes. This study found a significant difference in visual acuity parameters between centrally and para-centrally located apices in favor of the central apices [48].

Steppat presented that eyes with PMD following CXL procedures showed stable keratometric results and good visual acuity in all eyes except one [49].

A few case reports describing CXL for PMD have been published. All showed improvement and/or stabilization of visual acuity and keratometric parameters [50-52].

\section{CXL in keratectasia}

Keratectasia which is also called iatrogenic ectasia that occurs after laser surgery, such as laser-assisted in situ keratomileusis (LASIK) and photorefractive keratetomy (PRK), was first reported by Seiler et al. [53] in 1998.

Richoz et al. [54] showed that CXL could arrest the progression of keratectasia and improve CDVA and decrease K max. Aiming to correct the refractive error in patients with keratectasia, Kanellopoulos and Binder performed PRK combined with CXL in patients with keratectasia which happened 1 to 4 years after LASIK [36].

The residual corneal stromal bed less than $250 \mu \mathrm{m}$ could induce keratectasia and corneal flap plays little biomechanical effect. Kymionis and Wollensak presented the PTK-PRK-CXL method, that is, to perform PRK on flap after epithelium is removed with PTK, and then perform CXL with "Dresden protocol" [5,55]. CXL should be the first choice for patients with progressing keratectasia.

\section{Ectasia following photorefractive surgery}

Richoz presented a retrospective study that evaluated 26 eyes with PLE (23 eyes) and with ectasia after PRK (3 eyes) during a 2-year follow-up period. There was significant improvement in CDVA, $\mathrm{K}$-max and several topographic indices of corneal regularity (such as index of surface variance, index of vertical asymmetry, KCN index and central KCN index) [54].

In 2011, Kanellopoulos and Binder reported their data on a combination treatment using simultaneous CXL and PRK in patients with PLE. The goal was to use PRK to improve visual outcomes by normalizing the corneal surface, reducing irregular astigmatism and potentially reducing the refractive error - in addition to the corneal stabilization effect of corneal CXL [35].

\section{CXL in Infectious Keratitis}

Muller and Rau had demonstrated the anti-microorganism effect of UV rays and riboflavin could act as a photo-mediator to inactivate pathogens in plasma, platelets, and red blood cells [56-59].

Spoerl et al. [18] showed that CXL could increase the resistance of the cornea against enzymatic digestion. Besides, reactive oxygen species produced by CXL can eliminate or suppress the proliferation of pathogens through destroying the nucleic acids of pathogens $[18,60]$. Ferrari et al. [61] cured 1 eye with Escherichia coli derived keratitis by using CXL [61]. Li et al. [62] cured 8 eyes with fugal keratitis.

Müller et al. [63] performed CXL on eyes with corneal melting induced by variable pathogens including bacteria, fungi, and Acanthamoeba. To resolve the deficient corneal reepithelization, amniotic membrane implantation was performed 6 months after CXL. However, the outcomes of CXL on Acanthamoeba were different $[64,65]$. This may be explained by the fact that the effectiveness depth of CXL limited to the anterior $300 \mu \mathrm{m}$ and the treatment might be unsuccessful when microorganisms are penetrating too deep [11].

When CXL is combined with antibiotic drugs, the effect of crosslinking alone is uncertain. It is found that the success rate is higher for bacterial infections than fungal infections and that cross-linking should not be performed in eyes with prior herpes simplex [66].

Makdoumi et al. [67] and Martins et al. [68] implied that the parameters used in treatment of keratoconus might not fit for cure of keratitis. It seems that antimicrobial effect of cross-linking will be enhanced when dose of UVA is increased. 


\section{CXL in sclera-experimental study}

Wollensak et al. [69] proved that CXL increases the stiffness of porcine and human sclera. Thus, porcine sclera is a better study model for sclera collagen cross-linking.

\section{Cross-linking advantages}

The cross-linking technique has a lot of advantages: Is a procedure easy to perform, noticeably reduced time of procedure, is a localized selective treatment, the lack of scarring, availability of Riboflavin (nontoxic, hydrosoluble) and has a good stromal penetration.

\section{Safety parameters in cross-linking}

UVA cytotoxic threshold for the endothelium is $0,65 \mathrm{~J} / \mathrm{cm}^{2}$. UVA cytotoxic threshold for the lens is $70 \mathrm{~J} / \mathrm{cm}^{2}$. Riboflavin can decrease of about $95 \%$ of the UVA light intensity, allowing to remain below the endothelium cytotoxic threshold for corneal thickness over 440 microns.

\section{Known risks of CXL}

There are no known side effects for the corneal endothelium, lens and retina. Post surgery pain and feeling of foreign body for $24-48$ hours, till re-epitelization is complete. The patient can present hypertearing for 24-72 hours andtransitory corneal edema with visual haze for 30-60 days. Cross-linking treatment does not exclude the possibility of keratoplasty $[70,71]$

\section{Conclusions}

Cross-linking is a safe and efficient method of treatment in corneal ectasia in order to stop or arrest the progression of conus.

\section{Acknowledgement}

There are no other contributors to this article, other than the listed authors.

\section{References}

1. Siegel RC, Pinnell SR, Martin GR (1970) Cross-linking of collagen and elastin. Properties of lysyl oxidase. Biochemistry 9: 4486-4492. [Crossref]

2. Siegel RC (1974) Biosynthesis of collagen crosslinks: increased activity of purified lysyl oxidase with reconstituted collagen fibrils. Proc Natl Acad Sci USA 71: 48264830. [Crossref]

3. Seiler T, Hafezi F (2006) Corneal cross-linking-induced stromal demarcation line. Cornea 25: 1057-1059. [Crossref]

4. Spoerl E, Huhle M, Seiler T (1998) Induction of cross-links in corneal tissue. Exp Eye Res 66: 97-103. [Crossref]

5. Wollensak G, Spoerl E, Seiler T (2003) Riboflavin/ultraviolet-a-induced collagen crosslinking for the treatment of keratoconus. Am J Ophthalmol 135: 620-627. [Crossref]

6. Raiskup F, Spoerl E (2013) Corneal crosslinking with riboflavin and ultraviolet A. I principles. Ocul Surf 11: 65-74. [Crossref]

7. Andreassen TT, Simonsen AH, Oxlund H (1980) Biomechanical properties of keratoconus and normal corneas. Exp Eye Res 31: 435-441. [Crossref]

8. Elsheikh A, Brown M, Alhasso D, Rama P, Campanelli M, et al. (2008) Experimental assessment of corneal anisotropy. J Refract Surg 24: 178-187. [Crossref]

9. Hadley JC, Meek KM, Malik NS (1996) The effect of glycation on charge distribution and swelling behaviour of corneal and scleral collagen. Invest Ophthalmol Vis Sci 37: S1010.

10. Krueger RR, Ramos-Esteban JC (2007) How might corneal elasticity help us understand diabetes and intraocular pressure? J Refract Surg 23: 85-88. [Crossref]

11. Seiler T, Huhle S, Spoerl E, Kunath H (2000) Manifest diabetes and keratoconus: a retrospective case-control study. Graefes Arch Clin Exp Ophthalmol 238: 822-825. [Crossref]

12. Zadok D, Goldich Y, Barkana Y, Rasko A, Avni I (2008) Influence of UV-A-riboflavin corneal collagen cross-linking on biomechanical properties of keratoconic eyes. Paper presented at the 2008 ASCRS annual Meeting, Chicago

13. Müller LJ, Pels E, Vrensen GF (2001) The specific architecture of the anterior stroma accounts for maintenance of corneal curvature. Br J Ophthalmol 85: 437-443. [Crossref]

14. Braun E, Kanellopoulos J, Pe L Jankov M (2005) Ribovlavin/Ultraviolet-A-induced collagen cross-linking in the Management of Keratoconus. Invest Ophthalmol Vis Sci 46: 4964.

15. Luce DA (2005) Determining in vivo biomechanical properties of the cornea with an ocular response analyzer. J Cataract Refract Surg 31: 156-162. [Crossref]

16. Albe E (2008) Measuring corneal biomechanical properties in keratoconic eyes undergoing crosslinking. Cataract and Refractive Surgery Today Europe 5: 33-34

17. Wollensak G, Wilsch M, Spoerl E, Seiler T (2004) Collagen fiber diameter in the rabbit cornea after collagen crosslinking by riboflavin/UVA. Cornea 23: 503-507. [Crossref]

18. Spoerl E, Wollensak G, Seiler T (2004) Increased resistance of crosslinked cornea against enzymatic digestion. Curr Eye Res 29: 35-40. [Crossref]

19. Spoerl E, Wollensak G, Dittert DD, Seiler T (2004) Thermomechanical behavior of collagen-cross-linked porcine cornea. Ophthalmologica 218: 136-140. [Crossref]

20. Marshall J, Knox-Cartwright N (2009) Does CXL Promote Artificial Aging. J Cataract Refract Surg 04: 22-23. [Crossref]

21. Mazzotta C, Baiocchi S, Denaro R, Tosi GM, Caporossi T (2011) Corneal collagen cross-linking to stop corneal ectasia exacerbated by radial keratotomy. Cornea 30: 225 228. [Crossref]

22. Caporossi A, Mazzotta C, Baiocchi S, Caporossi T, Denaro R (2011) Age-Related Long-Term Functional Results after Riboflavin UV A Corneal Cross-Linking. $J$ Ophthalmol 2011: 608041. [Crossref]

23. Hafezi F, Mrochen M, Iseli HP, Seiler T (2009) Collagen crosslinking with ultraviolet-A and hypoosmolar riboflavin solution in thin corneas. J Cataract Refract Surg 35: 621624. [Crossref]

24. Elshawaf HI (2008) TCXL Trasepithelial corneal cross-linking. Paper presented at the IV International Congres of CXL, Dresden Germany

25. Koppen C, Wouters K, Mathysen D, Rozema J, Tassignon MJ (2012) Refractive and topographic results of benzalkonium chloride-assisted transepithelial crosslinking. $J$ Cataract Refract Surg 38: 1000-1008. [Crossref]

26. Spadea L, Mencucci R (2012) Transepithelial corneal collagen cross-linking in ultrathin keratoconic corneas. Clin Ophthalmol 6: 1785-1792. [Crossref]

27. Filippello M, Stagni E, O’Brart D (2012) Transepithelial corneal collagen crosslinking: bilateral study. J Cataract Refract Surg 38: 283-291. [Crossref]

28. Yoo SH, Dursun D, Dubovy S, Miller D, Alfonso E (2002) Iontophoresis for the treatment of paecilomyces keratitis. Cornea 21: 131-132. [Crossref]

29. Sarraf D, Lee DA (1994) The role of iontophoresis in ocular drug delivery. J Ocul Pharmacol 10: 69-81. [Crossref]

30. Arboleda A, Kowalczuk L, Savoldelli M, Klein C, Ladraa S, et al. (2014) Evaluating in vivo delivery of riboflavin with Coulomb-controlled iontophoresis for corneal collagen cross-linking: a pilot study. Invest Ophthalmol Vis Sci 55: 2731-2738. [Crossref]

31. Mencucci R, Ambrosini S, Paladini I, Favuzza E, Boccalini E, et al. (2015) Early effects of corneal collagen cross-linking by iontophoresis in ex vivo human corneas. Graefe's Arch Clin Exp Ophthalmol 253: 277-286.

32. Jacob S, Kumar DA, Agarwal A, Basu S, Sinha P (2014) Contact lens-assisted collagen cross-linking (CACXL): a new technique for cross-linking thin corneas. J Refract Surg 30: 366-372. [Crossref]

33. Mi S, Dooley EP, Albon J, Boulton ME, Meek KM, et al. (2008) The adhesion of LASIK-like $\mathrm{fl}$ aps in the cornea: effects of cross-linking, stromal fi broblasts and cytokine treatment: Presented in part in British Society for Matrix Biology Annual Meeting 2008, Cardiff, UK.

34. Todani A, Melki SA (2009) Late-onset epithelial ingrowth after laser in situ keratomileusis. J Cataract Refract Surg 35: 2022-2023. [Crossref]

35. Kanellopoulos; http://www.laservision.gr/US/PDFs/ASCRSBostonApr2010/1.pdf

36. Kanellopoulos AJ, Binder PS (2011) Management of corneal ectasia after LASIK 
with combined, same-day, topography-guided partial transepithelial PRK and collagen cross-linking: The Athens protocol. J Refract Surg 27: 323-331. [Crossref]

37. Ruckhofer J, Twa MD, Schanzlin DJ (2000) Clinical characteristics of lamellar channel deposits after implantation of Intacs. J Cataract Refract Surg 26: 1473-1479. [Crossref]

38. Coskunseven E, Jankov MR 2nd, Hafezi F, Atun S, Arslan E, et al. (2009) Effect of treatment sequence in combined intrastromal corneal rings and corneal collagen crosslinking for keratoconus. J Cataract Refract Surg 35: 2084-2091. [Crossref]

39. Ertan A, Karacal H, Kamburoğlu G (2009) Refractive and topographic results of transepithelial cross-linking treatment in eyes with intacs. Cornea 28: 719-723. [Crossref]

40. Saelens IE, Bartels MC, Bleyen I, Van Rij G (2011) Refractive, topographic, and visual outcomes of same-day corneal cross-linking with ferrara intracorneal ring segments in patients with progressive keratoconus. Cornea 30: 1406-1408. [Crossref]

41. Mazzotta C, Ramovecchi V (2014) Customized epithelial debridement for thin ectatic corneas undergoing corneal cross-linking: epithelial island cross-linking technique. Clin Ophthalmol 8: 1337-1343. [Crossref]

42. Caporossi A, Mazzotta C, Baiocchi S, Caporossi T (2010) Long-term results of riboflavin ultraviolet a corneal collagen cross-linking for keratoconus in Italy: The Siena eye cross study. Am J Ophthalmol 149: 585-593. [Crossref]

43. Wollensak G (2006) Crosslinking treatment of progressive keratoconus: new hope Curr Opin Ophthalmol 17: 356-360. [Crossref]

44. Corkin R (2009) CXL Indications and Patient Selection. J Cataract Refract Surg 04: 32-33.

45. Robin JB, Schanzlin DJ, Verity SM, Barron BA, Arffa RC, et al. (1986) Peripheral corneal disorders. Surv Ophthalmol 31: 1-36. [Crossref]

46. Koller T, Schumacher S, Fankhauser F 2nd, Seiler T (2013) Riboflavin/ultraviolet a crosslinking of the paracentral cornea. Cornea 32: 165-168. [Crossref]

47. Greenstein SA, Fry KL, Hersh PS (2012) Effect of topographic cone location on outcomes of corneal collagen cross-linking for keratoconus and corneal ectasia. $J$ Refract Surg 28: 397-405. [Crossref]

48. Lamy R, Netto CF, Reis RG, Procopio B, Porco TC, et al. (2013) Effects of corneal cross-linking on contrast sensitivity, visual acuity, and corneal topography in patients with keratoconus. Cornea 32: 591-596. [Crossref]

49. Steppat MH, Raiskup-Wolf F, Spörl E, Hoyer A, Pillunat LE (2008) Collagen cross linking in patients with pellucid marginal corneal degeneration (PMD) (poster presentation). ARVO.

50. Kymionis GD, Grentzelos MA, Portaliou DM, Karavitaki AE, Krasia MS, et al. (2010) Photorefractive keratectomy followed by same-day corneal collagen crosslinking after intrastromal corneal ring segment implantation for pellucid marginal degeneration. $J$ Cataract Refract Surg 36: 1783-1785. [Crossref]

51. Hassan Z, Nemeth G, Modis L, Szalai E, Berta A (2013) Collagen cross-linking in the treatment of pellucid marginal degeneration. Indian J Ophthalmol 62: 367-370. [Crossref]

52. Spadea L (2010) Corneal collagen cross-linking with riboflavin and UVA irradiation in pellucid marginal degeneration. J Refract Surg 26: 375-377. [Crossref]

53. Seiler T1, Koufala K, Richter G (1998) Iatrogenic keratectasia after laser in situ keratomileusis. J Refract Surg 14: 312-317. [Crossref]
54. Richoz O, Mavrakanas N, Pajic B, Hafezi F (2013) Corneal collagen cross-linking for ectasia after LASIK and photorefractive keratectomy: long-term results. Ophthalmol 120: 1354-1359. [Crossref]

55. Kymionis GD, Mikropoulos DG, Portaliou DM, Voudouragkaki IC, Kozobolis VP, et al. (2013) An overview of corneal collagen cross-linking (CXL). Adv Ther 30: 858-869. [Crossref]

56. Müller G, Goethe H, Herrmann R (1972) Ship drinking water disinfection using UV irradiation. II. Zentralblatt fur Bakteriologie, Parasitenkunde, Infektionskrankheiten und Hygiene. Erste Abteilung Originale. Reihe B: Hygiene, praventive Medizin 156 361-372.

57. Rau H (1960) A transportable apparatus for UV irradiation in final disinfection of patient rooms. Das Dtsch Gesundheitsw 15: 148-151. [Crossref]

58. Asano H, Lee CY, Fox-Talbot K, Koh CM, Erdinc MM, et al. (2007) Treatment with riboflavin and ultraviolet light prevents alloimmunization to platelet transfusions and cardiac transplants. Transplantation 84: 1174-1182. [Crossref]

59. Goodrich RP (2000) The use of riboflavin for the inactivation of pathogens in blood products. Vox Sang 78 Suppl 2: 211-215. [Crossref]

60. Raiskup F, Spoerl E (2013) Corneal crosslinking with riboflavin and ultraviolet A. Part II. Clinical indications and results. Ocul Surf 11: 93-108. [Crossref]

61. Micelli Ferrari T, Leozappa M, Lorusso M, Epifani E, Micelli Ferrari L (2009) Escherichia coli keratitis treated with ultraviolet A/riboflavin corneal cross-linking: a case report. Eur J Ophthalmol 19: 295-297. [Crossref]

62. Li Z, Jhanji V, Tao X, Yu H, Chen W (2013) Riboflavin/ultravoilet light-mediated crosslinking for fungal keratitis. Br J Ophthalmol 97: 669-671. [Crossref]

63. Müller L, Thiel MA, Kipfer-Kauer AI, Kaufmann C (2012) Corneal cross-linking as supplementary treatment option in melting keratitis: a case series. Klin Monbl Augenheilkd 229: 411-415. [Crossref]

64. Morén H, Malmsjö M, Mortensen J, Ohrström A (2010) Riboflavin and ultraviolet a collagen crosslinking of the cornea for the treatment of keratitis. Cornea 29: 102-104. [Crossref]

65. Rama P, Di Matteo F, Matuska S, Paganoni G, Spinelli A (2009) Acanthamoeba keratitis with perforation after corneal crosslinking and bandage contact lens use. $J$ Cataract Refract Surg 35: 788-791. [Crossref]

66. Meek KM, Hayes S (2013) Corneal cross-linking-a review. Ophthalmic Physiol Opt 33: 78-93.

67. Makdoumi K, Bäckman A, Mortensen J, Crafoord S (2010) Evaluation of antibacterial efficacy of photo-activated riboflavin using ultraviolet light (UVA). Graefes Arch Clin Exp Ophthalmol 248: 207-212. [Crossref]

68. Martins SA, Combs JC, Noguera G, Camacho W, Wittmann P, et al. (2008) Antimicrobial efficacy of riboflavin/UVA combination $(365 \mathrm{~nm})$ in vitro for bacterial and fungal isolates: a potential new treatment for infectious keratitis. Invest Ophthalmol Vis Sci 49: 3402-3408. [Crossref]

69. Wollensak G, Spoerl E (2004) Collagen crosslinking of human and porcine sclera. $J$ Cataract Refract Surg 30: 689-695. [Crossref]

70. Sorkin N, Varssano D (2014) Corneal collagen crosslinking: a systematic review. Ophthalmologica 232: 10-27. [Crossref]

71. Zhang X, Tao XC, Zhang J, Li ZW, Xu YY, et al. (2015) A Review of Collagen CrossLinking in Cornea and Sclera. J Ophthalmol 2015: 289467. [Crossref]

Copyright: (C2016 Nicula C. This is an open-access article distributed under the terms of the Creative Commons Attribution License, which permits unrestricted use, distribution, and reproduction in any medium, provided the original author and source are credited. 